\title{
Intrinsic timescales of variability in a marine plankton model
}

\author{
Benjamin Mayersohn ${ }^{\mathrm{a}, \mathrm{b}}$, K. Shafer Smith ${ }^{\mathrm{a}, \mathrm{b}, *}$, Inès Mangolte ${ }^{\mathrm{c}}$, Marina Lévy $^{\mathrm{c}}$ \\ ${ }^{a}$ Courant Institute of Mathematical Sciences, New York University, New York, New York 10012, USA \\ ${ }^{b}$ Center for Prototype Climate Modeling, New York University, Abu Dhabi, UAE \\ ${ }^{c}$ Sorbonne Université (CNRS/IRD/MNHN), Laboratoire d'Océanographie et du Climat (LOCEAN), Institut Pierre, Simon \\ Laplace (IPSL), Paris Cedex 05 75252, France
}

\begin{abstract}
Phytoplankton are known to exhibit temporal variability in biomass and community composition. While physically driven sources of variability have been studied extensively, ecosystems often exhibit complicated intrinsic dynamics that are not as well understood. As a first step towards assessing the contribution of this intrinsic variability to the total variability in the ocean, we examine the temporal scales of intrinsic variability in a marine plankton model suitable for use in climate model projections. Our rationale is that a better understanding of the time scales over which intrinsic variability manifests could help in the attribution of observed variability. Our model includes multiple phytoplankton, dissolved inorganic nutrients, and zooplankton and supports two oscillatory mechanisms: "R-oscillations", corresponding to patterns of species succession and associated with changes in resources, and "Z-oscillations", corresponding to changes in total phytoplankton biomass due to predator-prey interactions.

Over a wide range of model parameters, we found that while Z-oscillations typically occurred on time scales not exceeding 60 days, R-oscillations ranged from roughly 100 to 900 days under predation-free conditions, and R-oscillations occurred on longer time scales when interacting with Z-oscillations. Thus the two kinds of oscillations can be easily distinguished. At high grazing rates, we identified aperiodic cases where the dominant period never resolved, with distinct regimes emerging over decadal (or longer) time scales. These chaotic regime shifts are likely highly dependent on the model parameters and structure. More work must be done to understand how these oscillations interact with physical forcings.
\end{abstract}

Keywords: Intrinsic variability, phytoplankton, predator-prey dynamics

\section{Introduction}

Phytoplankton communities exhibit different temporal modes of variability both in total biomass and community structure. Understanding the drivers of this natural variability is a prerequisite for confidently identifying changes in the ecosystem attributable to anthropogenic forcing. Ocean color observations of chlorophyll-a (a proxy for phytoplankton biomass), for example, have revealed variability at intraseasonal (weeks to months), seasonal, and interannual ( $>1$ year) time scales over most open ocean regions (Behrenfeld et al., 2006; Martinez et al., 2009; Resplandy et al., 2009; Vantrepotte and Mélin, 2011; Thomalla et al.,

*Corresponding author at: Courant Institute of Mathematical Sciences, New York University, New York, New York 10012, USA. Email address: kss3@nyu.edu 
2011; Demarcq et al., 2012; Mayot et al., 2017; Salgado-Hernanz et al., 2019; Keerthi et al., 2020; Huisman et al., 2006). In-situ measurements of phytoplankton species abundances, as well as observations from ocean color remote sensing (which has been used to infer phytoplankton functional types and sizes), reveal that community structure varies over a similar range of time scales to chlorophyll-a (Alvain et al., 2008; d'Ovidio et al., 2010; Demarcq et al., 2012; Rousseaux and Gregg, 2015; Mayot et al., 2017; Dakos et al., 2009). This wide range of time variability in phytoplankton communities is also seen in global biogeochemical models of the ocean (Aumont et al., 2018; Dutkiewicz et al., 2019).

Much of the variability found in marine phytoplankton communities can be attributed to variability in the physical environment in which they evolve. A typical example is the spring phytoplankton bloom, which is driven by seasonal changes in light and vertical mixing (Platt et al., 2009; Sathyendranath et al., 2015, and references therein), and which explains the largest part of the time variability (Demarcq et al., 2012). At the intraseasonal timescale, variability can be driven by intraseasonal basin-scale climate modes such as the Madden-Julian oscillation (Resplandy et al., 2009), synoptic atmospheric forcing due to storms (Fauchereau et al., 2011; Carranza and Gille, 2014) and tropical cyclones (Menkes et al., 2016), or by oceanic mesoscale and submesoscale processes acting at even smaller spatial scales (Mahadevan et al., 2012; Lévy et al., 2018; Poggiale et al., 2013; Keerthi et al., 2020). At lower frequencies (interannual to multidecadal timescales), part of the variability is forced by large-scale, low-frequency climate modes such as the Pacific Decadal Oscillation, the El Nino Southern Oscillation or the Atlantic Multidecadal Oscillation (Chavez et al., 2011, and references therein).

However, phytoplankton also exhibit complex dynamics even in the absence of external variability. Empirical evidence for such intrinsic variability is difficult in the natural environment because the external forcing is always present. However, it can be seen in dedicated laboratory experiments where the experimental conditions are artificially held constant. For example, Fussmann et al. (2000) have demonstrated the potential for predator-prey oscillations in a culture with one nutrient, one phytoplankton species and one zooplankton species in a continuous flow-through chemostat. More recently, predator-prey oscillations have been observed to persist over several predator-prey cycles in a controlled culture of planktonic rotifers and unicellular green algae in the laboratory (Blasius et al., 2019; Hastings, 2020). Benincà et al. (2008) conducted a long-term (> 8 years) laboratory mesoscosm experiment with a more complex plankton food web (two nutrients and ten functional groups) that exhibited striking fluctuations of different periodicities (from 15 days to 225 days), attributable only to interactions between species in the food web.

Phytoplankton intrinsic variability is a recurrent topic in theoretical ecology. Limit cycles - and sometimes chaos (Benincà et al., 2015) — in phytoplankton populations are emergent properties of mathematical models of interspecies interactions. These models, usually constructed to represent a system in a chemostat under constant conditions (Gothlich and Oschlies, 2015), have shown that internal variability may result from two fairly different processes: competition between different phytoplankton species for limiting resources (Tilman, 1977; Huisman and Weissing, 1999, 2001) and predator-prey interactions (Gilpin, 1979; Edwards and Brindley, 1996). The zero-dimensional food web models developed for these ecological studies are similar to the ones used for global biogeochemical studies, where the plankton equations are solved in three dimensions and are embedded into an ocean circulation model. We might therefore expect internal 
variability to manifest in these forced 3D models.

In the natural environment, it is difficult to disentangle internal variability from forced variability. An improved understanding of phytoplankton intrinsic variability is a prerequisite to confidently identify the phytoplankton trends attributable to physical forcings, which are likely to dominate in the open ocean (and in 3D models of the open ocean) but might not explain all of the observed variability. As a first step towards assessing how much intrinsic variability in phytoplankton biomass and community structure contributes to the total variability in the ocean, our objective is to examine the temporal scales of intrinsic variability in a marine plankton model. A better understanding of the time scales over which intrinsic variability manifests could help in the attribution of observed variability.

In this study, we focus on the two types of intrinsic variability mentioned previously: those due to competition between phytoplankton for multiple resources, which we call R-oscillations, and those due to predator-prey interactions, which we call Z-oscillations. These two kinds of oscillations have been studied in isolation, but never together to our knowledge. Here we ask specifically: (1) what are the time scales for each type of oscillation, (2) how do they interact, and (3) what is their sensitivity to a realistic range of model parameters? To address these questions, we have developed a moderately-complex ecosystem model that supports both kinds of intrinsic variability, and we use it to explore the time scales of variability that emerge under constant environmental forcing in a chemostat system. The closest analogue of our chemostat scenario to a physical regime is a low-latitude eastern boundary upwelling region, such as the Benguela (Messié et al., 2009). High nutrient delivery via upwelling, combined with relatively low seasonality due to its proximity to the equator, provide an optimal environment for any existing mechanisms of intrinsic variability to persist. The present paper can be considered the first entry in a two-part study; the second step will be to investigate how these intrinsic variations manifest under time-varying external forcings.

A key goal in constructing our model is to bridge the gap between highly idealized conceptual models focused on specific ecological interactions, and the much more complex biogeochemical components of Earth-system models used for global climate simulations. The latter class of models achieved a milestone with Fasham et al. (1990), who developed a nitrogen-based biogeochemical model used in a General Circulation Model for the North Atlantic Ocean (Sarmiento et al., 1993), and Aumont et al. (2003), who investigated the effect of multi-nutrient limitation on the biological carbon pump. Building from these first biogeochemical models, the PISCES model (Aumont et al., 2015) was incorporated into the IPSL-CM5 earth system model as part of CMIP5 (Bopp et al., 2013). The even-more-complex Darwin ecosystem model (Follows et al., 2007) was used by Prowe et al. (2014) to examine the effect of phytoplankton diversity on primary production in response to environmental changes. Wherever possible, we follow common choices in the class of models described above in determining model representations of processes and parameter values.

Section 2 introduces the model that we will use, including the equations and the numerical integration scheme (a simplified version of the equations is also presented in Appendix A). Section 3 presents four example simulations: two that exhibit each type of oscillation in isolation, and two that demonstrate the complexity of the full model. Section 4 explores the sensitivity of the results to key parameters involved in the phytoplankton growth and decay rates, using multidimensional sweeps over model parameters adding up to 6400 separate simulations. The results demonstrate the emergent regimes arising from the underlying 
oscillations. Finally in section 5 we discuss the implications of these results, in particular how the emergent frequencies depend on the presence of and interaction between different kinds of oscillations. We discuss how the time scales of intrinsic variability that emerges compares with time scales of external forcings in the open ocean. Ideas regarding future experiments to address this topic are also presented.

\section{A chemostat-like model for studying intrinsic variability}

Here we develop a chemostat-like model, with a continuous inflow of nutrients and without variations in light or temperature. This is arguably the simplest system that mimics a physical setting — something roughly like a low-latitude Eastern boundary upwelling system (see e.g. Messié et al. (2009)), with a high rate of nutrient influx from the deep ocean and relatively low seasonality — yet permits only variability driven by internal dynamics. The model shares common terms with other biogeochemical models, and all ecological parameters are assigned reasonable values based on the literature. While our model does support oscillatory behavior that is not common in other models, we believe that these features are reasonably explained by the general complexity of ecosystem dynamics.

To represent the dynamics discussed in the introduction, the model requires multiple nutrient, phytoplankton and zooplankton compartments. Huisman and Weissing (2001) have shown that R-oscillations start emerging when the number of species and the number of resources is equal or larger than three. And of course, Z-oscillations require the presence of at least one phytoplankton and one zooplankton species. As is common in biogeochemistry models of this kind (e.g. Dutkiewicz et al., 2009; Aumont et al., 2015), we include two size classes for phytoplankton: small species (gleaners) that thrive in nutrient-poor environments, and larger species (opportunists) that dominate in nutrient-rich environments.

Given these constraints, we therefore include two phytoplankton size classes with three phytoplankton each, for six phytoplankton in total: $P_{1}^{s}$ through $P_{3}^{s}$ are small species, while $P_{1}^{l}$ through $P_{3}^{l}$ are large species. The different phytoplankton compartments within the same size class represent distinct species (e.g. prochlorococcus and synechococcus are both picophytoplankton), rather than members of the same species with different ecological properties. Two species of zooplankton are also included: $Z^{s}$ is a microzooplankton species that consumes small phytoplankton, while $Z^{l}$ is a larger mesozooplankton species that consumes both large phytoplankton and microzooplankton. The model includes three dissolved inorganic resource compartments $R_{j}$, representative of nitrogen $\left(R_{1}, \mu \mathrm{mol} / \mathrm{m}^{3} \mathrm{~N}\right)$, phosphorus $\left(R_{2}, \mu \mathrm{mol} / \mathrm{m}^{3} \mathrm{PO}_{4}\right)$, and iron $\left(R_{3}, \mu \mathrm{mol} / \mathrm{m}^{3} \mathrm{Fe}\right)$. We restrict our model to three nutrients because it is the minimum number required to produce R-oscillations. Iron is chosen over silicate because the need for silicate is specific to large diatoms. Also, for simplicity, the model does not distinguish between different forms of nitrogen such as nitrate and ammonium. Phytoplankton and zooplankton compartments have units $\mu$ mol $\mathrm{C}$, with stoichiometric conversions for the phytoplankton compartments described below. The model is configured in a chemostat setting, with relaxation of resource $R_{j}$ toward target values $S_{j}$ at a dilution rate $\tau$. Biomass is removed through mortality and via outflux at the same dilution rate $\tau$; explicit remineralization and settling are omitted. Phytoplankton mortality is linear as is typical in these models (Cropp and Norbury, 2009). Quadratic zooplankton mortality parameterizes density-dependent losses such as viral infection, and also acts as a closure term for predation 


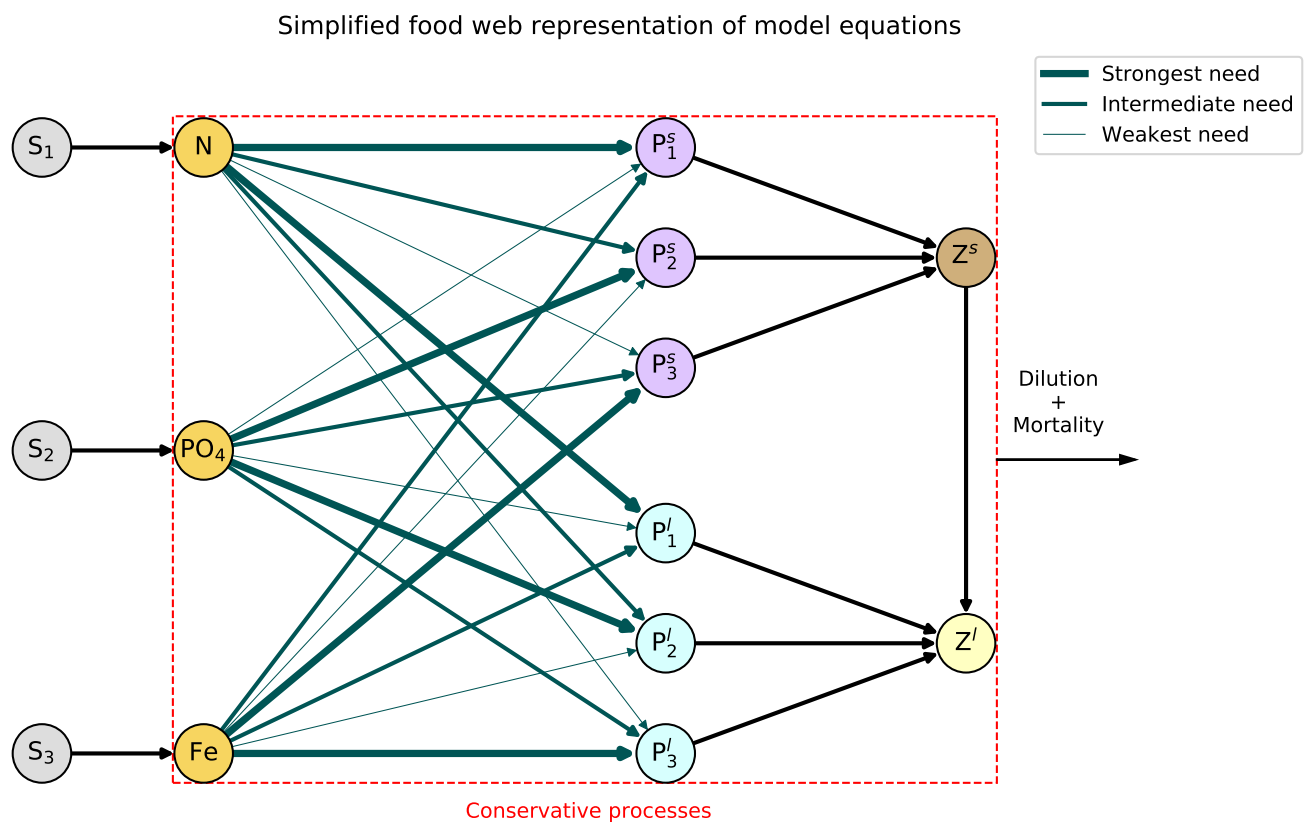

Figure 1: A food web representation of the model equations. Phytoplankton are controlled from the bottom-up by externally-supplied nutrients and from the top-down by zooplankton. The widths of the arrows pointing to a given phytoplankton depend on its relative needs for each nutrient. Conservative processes, or exchanges that do not result in any loss of mass from the system, are contained within the dashed red box. That is, without the deep nutrient supply; natural phytoplankton and zooplankton mortality terms; and loss of biomass through dilution, the system would exhibit biomass conservation.

by species unrepresented in this model (Aumont et al., 2015). A model schematic is shown in Figure 1. A simplified version of this model is provided in Appendix A.

\subsection{Model equations}

The model equations are

$$
\begin{aligned}
\frac{d R_{j}}{d t} & =\tau\left(S_{j}-R_{j}\right)-\sum_{i=1}^{3} C_{j i}\left[\mu^{s} \min _{j} \frac{R_{j}}{K_{j i}^{s}+R_{j}} P_{i}^{s}+\mu^{l} \min _{j} \frac{R_{j}}{K_{j i}^{l}+R_{j}} P_{i}^{l}\right], \\
\frac{d P_{i}^{s}}{d t} & =-\tau P_{i}^{s}+\left[\mu^{s} \min _{j} \frac{R_{j}}{K_{j i}^{s}+R_{j}}-m_{P}-\frac{g^{s} Z^{s}}{K_{Z}+P_{\mathrm{tot}}^{s}}\right] P_{i}^{s}, \\
\frac{d P_{i}^{l}}{d t} & =-\tau P_{i}^{l}+\left[\mu^{l} \min _{j} \frac{R_{j}}{K_{j i}^{l}+R_{j}}-m_{P}-\frac{g^{l} Z^{l}}{K_{Z}+Z^{s}+P_{\mathrm{tot}}^{l}}\right] P_{i}^{l}, \\
\frac{d Z^{s}}{d t} & =-\tau Z^{s}+\frac{g^{s} Z^{s}}{K_{Z}+P_{\mathrm{tot}}^{s}} P_{\mathrm{tot}}^{s}-\left[\frac{g^{l} Z^{l}}{K_{Z}+Z^{s}+P_{\mathrm{tot}}^{l}}+m_{Z} Z^{s}\right] Z^{s} \\
\frac{d Z^{l}}{d t} & =-\tau Z^{l}+\frac{g^{l} Z^{l}}{K_{Z}+Z^{s}+P_{\mathrm{tot}}^{l}}\left(Z^{s}+P_{\mathrm{tot}}^{l}\right)-m_{Z}\left(Z^{l}\right)^{2}
\end{aligned}
$$

where $i, j=1,2,3$, and $P_{\mathrm{tot}}^{s, l}=\sum_{i=1}^{3} P_{i}^{s, l}$.

The phytoplankton growth rates are equal to a nutrient limitation factor scaled by the maximum growth rate $\mu$. Nutrient limitation is set dynamically by the smallest Monod growth factor, which depends on the values of $K_{j i}$. Large phytoplankton species (opportunists) grow faster and require more nutrient than small phytoplankton species (gleaners), allowing the former to thrive in high-nutrient environments, and the latter 


\begin{tabular}{|c|c|c|c|}
\hline Parameter & Default Value & Units & Description \\
\hline$\tau$ & 0.04 & day $^{-1}$ & Nutrient restoring rate $^{1}$ \\
\hline$S_{j}$ & $18.1,1.21,1.21 \times 10^{-3}$ & {$\left[R_{j}\right]$} & Deep ocean nutrient source values ${ }^{1}$ \\
\hline$\mu^{s}, \mu^{l}$ & $0.308,0.616$ & day $^{-1}$ & Maximum phytoplankton growth rates ${ }^{2}$ \\
\hline$m_{P}$ & 0.1 & day $^{-1}$ & Phytoplankton mortality rate ${ }^{2}$ \\
\hline$r_{j}$ & $0.15,0.01,1 \times 10^{-5}$ & $\frac{\left[R_{j}\right]}{\mu \mathrm{mol} / \mathrm{m}^{3} \mathrm{C}}$ & Nutrient : Carbon ratios ${ }^{3}$ \\
\hline$c_{\min }, c_{\max }$ & $0.9,1.3$ & & Stoichiometric scaling factors (Eq. 3) \\
\hline$\kappa_{j}^{s}=\frac{1}{4} \kappa_{j}^{l}$ & $0.15,0.01,1 \times 10^{-5}$ & {$\left[R_{j}\right]$} & Nutrient uptake half-saturation constants ${ }^{2}$ \\
\hline$k_{\min }, k_{\max }$ & $0.7,1.1$ & & Nutrient half-saturation scaling factors (Eq. 4) \\
\hline$g^{s}, g^{l}$ & $1.5,0.5$ & day $^{-1}$ & Grazing rates ${ }^{4}$ \\
\hline$K_{Z}$ & 10 & $\mu \mathrm{mol} / \mathrm{m}^{3} \mathrm{C}$ & Grazing half-saturation constant ${ }^{4}$ \\
\hline$m_{Z}$ & 0.015 & $\left(\mu \mathrm{mol} / \mathrm{m}^{3} \mathrm{C} \cdot \text { day }\right)^{-1}$ & Zooplankton mortality rate ${ }^{5}$ \\
\hline
\end{tabular}

${ }^{1}$ Typical for the Benguela upwelling system (Messié et al., 2009)

${ }^{2}$ Follows et al. (2007)

${ }^{3} r_{1}=\mathrm{N}: \mathrm{C}, r_{2}=\mathrm{PO}_{4}: \mathrm{C}, r_{3}=$ Fe:C (Redfield, 1934)

${ }^{4}$ Aumont et al. (2015)

${ }^{5}$ Messié and Chavez (2017)

Table 1: Definitions and default values for model parameters. Subscript $j=1,2,3$. The notation $\left[R_{j}\right]$ means "the units of $R_{j}$ ", which are $\left[R_{1}\right]=\mu \mathrm{mol} \mathrm{N},\left[R_{2}\right]=\mu \mathrm{mol} \mathrm{PO}_{4}$, and $\left[R_{3}\right]=\mu \mathrm{mol} \mathrm{Fe}$. References for default values are given where appropriate in footnotes. 
to overtake competitors in low-nutrient environments. This is modeled by setting $\mu^{l}=2 \mu^{s}$ (see Table 1 for values) and $K_{j i}^{l}=4 K_{j i}^{s}$.

\subsection{Nutrient source, stoichiometry, and uptake limitation}

We set the nutrient source relaxation rate $\tau=0.04$ days $^{-1}$ and deep nitrogen concentration value $S_{1}=$ $18.1 \mu \mathrm{mol} \mathrm{N}$, which are characteristic of, for example, the Benguela upwelling system (Messié et al., 2009). The other deep nutrient concentrations are derived from $S_{1}$ through the Redfield ratios $r_{j}$ (Table 1), i.e.

$$
\frac{S_{1}}{r_{1}}=\frac{S_{2}}{r_{2}}=\frac{S_{3}}{r_{3}}
$$

The phytoplankton stoichiometric coefficients $C_{j i}$ in the nutrient uptake term convert increases in biomass to corresponding losses in the inorganic nutrient pools; large and small phytoplankton share the same stoichiometry. The Redfield ratio is an average of the stoichiometry found across a variety of phyotoplankton species (Klausmeier et al., 2004), and so we include some variation in the stoichiometry for each modeled species. The stoichiometry matrix $C_{j i}$ is constructed such that for a given nutrient and phytoplankton group, one species has exactly the Redfield value, another species has a slightly larger value controlled by $c_{\max }>1$, and the third species has a slightly smaller value controlled by $c_{\min }<1$. Dividing each row by $r_{j}$, the matrix is

$$
\frac{C_{j i}}{r_{j}}=\left(\begin{array}{ccc}
c_{\max } & 1 & c_{\min } \\
c_{\min } & c_{\max } & 1 \\
1 & c_{\min } & c_{\max }
\end{array}\right)
$$

So for example, $P_{1}, P_{2}$, and $P_{3}$ have the largest, intermediate, and smallest stoichiometric values for nitrogen, respectively. This is reflected in Figure 1, with the thickness of the lines between the phytoplankton and nutrients corresponding to the magnitudes of the stoichiometric coefficients.

Half-saturation constants for a given nutrient and a specific size class (gleaners, say) are similar between species in that size class. Denoting $\kappa_{j}^{s, l}$ as the typical half-saturation value for resource $j$ and size class $s$ or $l$ (See Table 1 for values), the half-saturation matrix has a similar structure to the stoichiometric matrix, with

$$
\frac{K_{j i}^{s, l}}{\kappa_{j}^{s, l}}=\left(\begin{array}{ccc}
1 & k_{\min } & k_{\max } \\
k_{\max } & 1 & k_{\min } \\
k_{\min } & k_{\max } & 1
\end{array}\right)
$$

where $k_{\max }>1$ and $k_{\min }<1$ designate the entries with the largest and smallest coefficients per row (species), respectively.

\subsection{Model numerics and spinup}

The model is written in Python 3.6 and integrated in time with the SciPy odeint library (Millman and Aivazis, 2011). This module acts as a wrapper for ODEPACK's LSODA solver that automatically switches between Adams (non-stiff) and BDF (stiff) integration methods when appropriate (Hindmarsh, 1982; Petzold, 1983). The time series for each of the model compartments is stored in intervals of one day.

All simulations were run for 200 years, with the exception of one 500 year simulation to illustrate a longer-term phenomenon, depicted in Figure 6. We have observed that the spinup time for these simulations 
is typically around 1-2 years. But because some of our simulations have very long periods of oscillation and may even exhibit aperiodic behavior — we took a conservative approach and only used the last 150 years of each simulation for analysis.

\section{Example simulations: Resource oscillations, predator-prey oscillations and their interactions}

The model described above is designed to capture two primary mechanisms of intrinsic variability: competition between phytoplankton for resources (R-oscillations), and predator-prey interactions (Z-oscillations). In this section we consider four basic example simulations. The first two are designed to understand the nature of each oscillation independently. The NoPred simulation removes both zooplankton, in order to highlight how resource competition can give rise to coexistence amongst phytoplankton in a similar size class. The SimpleCom (for "simple competition") case retains only two phytoplankton species, one from each of the two size classes, thus allowing only predator-prey interactions. The third case, called WeakPred, is an example of the full system that uses parameters given in Table 1. In this case, the two types of oscillations are both present, but remain distinct enough to isolate in their time-series and frequency spectra. The last case, termed StrongPred, employs increased grazing rates; the result is a simulation in which the types of oscillations interact in complex ways, producing time series that exhibit broadband chaotic behavior.

\subsection{Case NoPred: Isolated R-oscillations}

The first example, which we call NoPred, removes predators from the model by disabling all terms that contain $Z^{s}$ and $Z^{l}$. Figure 2 shows time series and frequency spectra for the nutrients and small phytoplankton species. The spectra were computed using the discrete Fourier transform (DFT) after centering the data around zero and multiplying the remainder by a Hamming window. In the caption and throughout the paper, we use the term "dominant period" to denote the reciprocal of the frequency with the largest amplitude in the spectrum. If the dominant period is equal to the length of the series, then we say that the series has not equilibrated and we do not assign a dominant period.

For this particular parameter regime, the large phytoplankton are not shown because they die out via competitive exclusion. The large phytoplankton have higher growth rates, but larger half-saturation coefficients, which means they require greater ambient nutrient concentrations to compete successfully with gleaners; an increase in the nutrient input rate $\tau$ or deep nutrient concentrations $S_{j}$, for example, would lead to the elimination of small phytoplankton instead. Peaks in the individual small phytoplankton alternate roughly every 90 days. Every time an individual species peaks, one also sees peaks in both the total phytoplankton $P_{\text {tot }}^{s}$ and in the nutrient compartments. The correspondence between a peak in $\mathrm{PO}_{4}$ and a peak in $P_{2}^{s}$ (as well as a peak in the total phytoplankton) is highlighted by the vertical red lines. The same correspondence occurs between $P_{s}^{1}$ and $\mathrm{N}$, and between $P_{s}^{3}$ and Fe. The oscillations of total phytoplankton biomass are small compared with fluctuations in the individual compartments.

These R-oscillations are well described by the resource-ratio hypothesis of species succession (Tilman, 1985). Such oscillations depend on two factors: differences in the phytoplankton stoichiometric coefficients $C_{j i} / r_{j}$ (3) across the nutrient pools, and differences in the half-saturation coefficients $K_{j i} / \kappa_{j}(4)$ between species. The driving mechanism behind R-oscillations can be summarized in two steps: 


\section{NoPred}

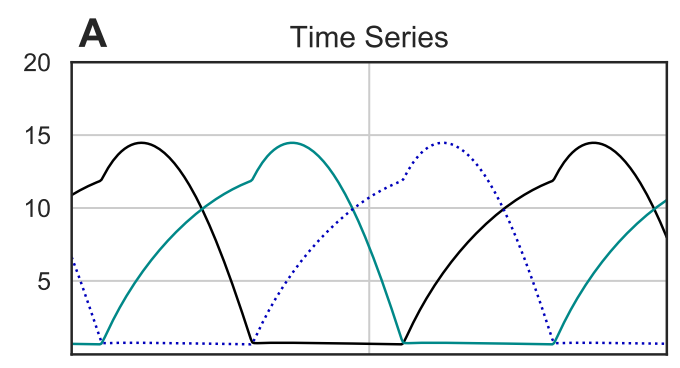

B

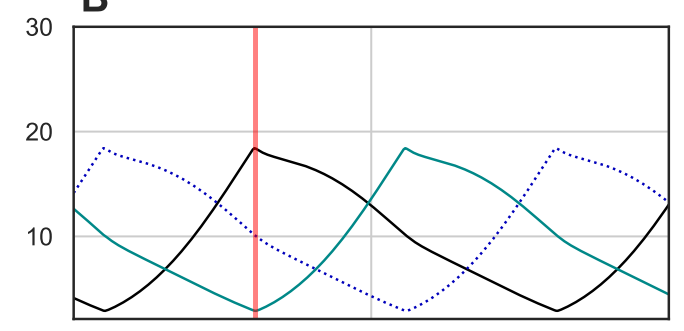

C

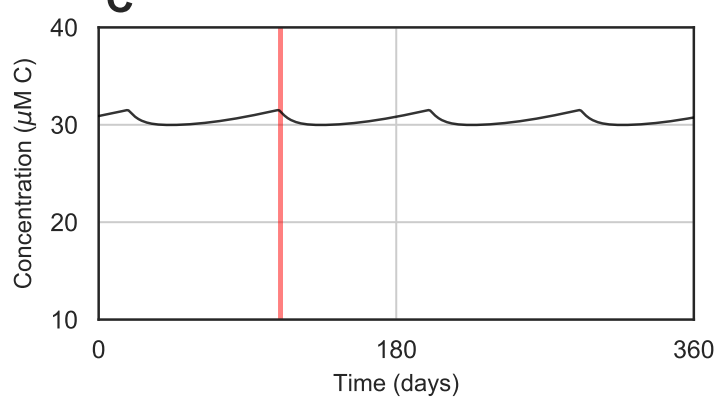

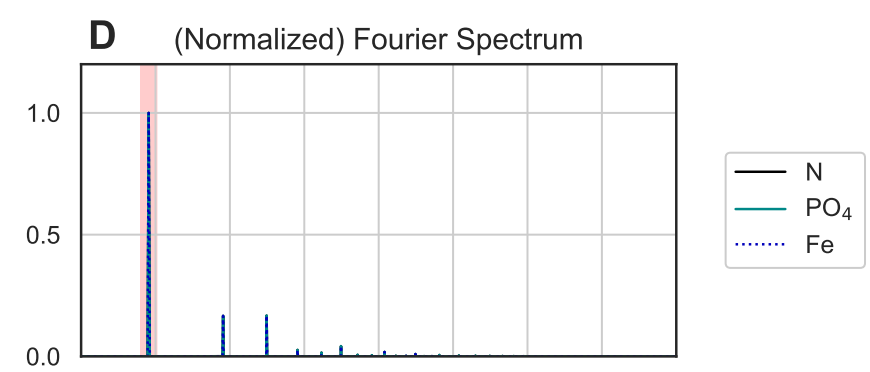

E
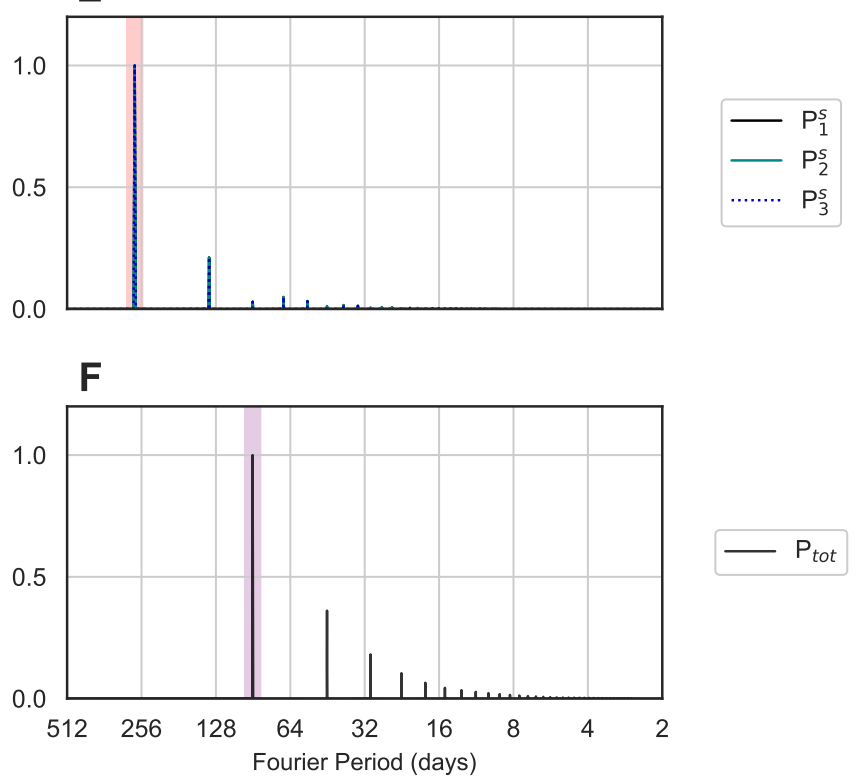

Figure 2: Time series of the last year (left column, panels A-C) and frequency spectra of the last 50 years (right column, panels D-F) from a 200 year simulation of the NoPred (isolated R-oscillations) scenario. The rows correspond to (top) nutrients, (middle) surviving phytoplankton (large phytoplankton do not survive in this scenario), and (bottom) total phytoplankton. See legends for curve identification. In panel B, the red vertical line corresponds to a peak in $P_{1}^{s}$, while the blue lines correspond to peaks in $P_{1}^{l}$. The purple lines in panel C correspond to peaks in the small and large zooplankton. These peak indicators were all copied into panel D to demonstrate that zooplankton peaks follow those of the phytoplankton. The red shading in panels $\mathrm{D}$ and $\mathrm{E}$ indicates the dominant periods for the phytoplankton and nutrients (all share the same peak at approx. 273 days), and the purple shading in panel $\mathrm{F}$ indicates the dominant period for the total phytoplankton (approx. 91 days). 
1. The current dominant phytoplankton depletes the nutrient for which it has the largest $C_{j i} / r_{j}$, at a rate proportional to $c_{\max }$.

2. The phytoplankton with the largest growth rate at low values of the newly-depleted nutrient will become the next dominant phytoplankton. By construction, this phytoplankton is the one with the minimum half-saturation constant $K_{j i} / \kappa_{j}$ (proportional to $k_{\min }$ ) for this given nutrient.

Let us say that $P_{1}^{s}$ is dominant. For this phytoplankton, the largest nutrient need (largest $\left.C_{j i} / r_{j}\right)$ is for nitrogen. Thus, $P_{1}^{s}$ depletes nitrogen first as it grows. This sets up $P_{2}^{s}$, which has the largest growth rate at low values of nitrogen (lowest $K_{j i} / \kappa_{j}$ ) compared with its competitors, to become the next dominant species. This two-step process repeats as $P_{2}^{s}$ depletes phosphorus and $P_{3}^{s}$ is primed to thrive when this nutrient is limiting. Finally, $P_{3}^{s}$ depletes iron, allowing $P_{1}^{s}$ to thrive and completing a full cycle. In this case, $c_{\text {max }}$ and $k_{\min }$ are two key parameters that regulate this oscillatory mechanism. Increasing $c_{\max }$ accelerates the depletion of what will become the next limiting nutrient in the system. Decreasing $k_{\text {min }}$ enhances the growth rate of the next dominant species, resulting in a faster invasion.

With the chosen parameter set, individual phytoplankton oscillations take about 273 days to complete, while total phytoplankton biomass cycles take one third as long (91 days) due to symmetries in the oscillations of the individual compartments; these symmetries emerge because the stoichiometric matrix (3) and halfsaturation matrix (4) are circulant. Also, note that fluctuations in the total phytoplankton concentrations are relatively small compared to oscillations in the individual compartments. This is because R-oscillations primarily represent variability at the species level.

\subsection{Case SimpleCom: Isolated Z-oscillations}

The second example, which we call SimpleCom, is obtained by including both zooplankton, but just one large and one small phytoplankton with the same stoichiometric coefficients: $P_{1}^{s}$ and $P_{1}^{l}$. In this case, nitrogen will always be the limiting nutrient, so the stoichiometric diversity that generates oscillations among competing species is removed, while predator-prey cycles are left intact.

While R-oscillations primarily represent variability at the species level, Z-oscillations are a form of total biomass variability that occurs when zooplankton growth rates are sufficiently large. They induce significant fluctuations in both the total phytoplankton and individual species concentrations. In panel G of Figure 3 we see that peaks in the zooplankton time series always follow peaks in the phytoplankton series. As is typical of a predator-prey model, zooplankton concentrations evolve in the direction of phytoplankton biomass changes, while phytoplankton concentrations evolve inversely to zooplankton biomass changes. In this case, because of the zooplankton size selectivity, the small and large phytoplankton alternate dominance. The large and small zooplankton alternate dominance as well, with each following peaks in their target prey. But small zooplankton are restricted to small bursts following peaks in small phytoplankton, as large zooplankton exhibit top-down control on their biomass. The dominant period of the total phytoplankton in this scenario is about 40 days. The dominant period of $P_{1}^{s}$ is about 81 days, while the double-peaked large phytoplankton has a dominant period of about 27 days. 


\section{SimpleCom}

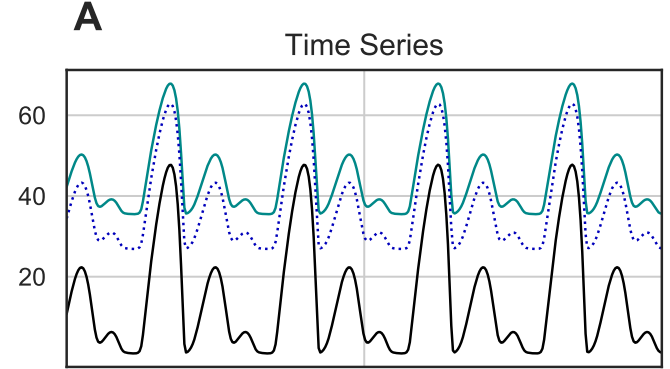

B

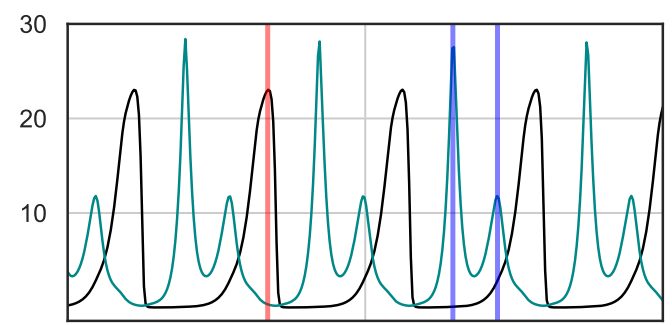

C

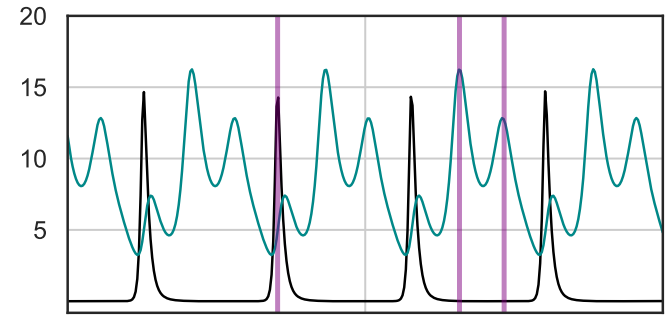

D

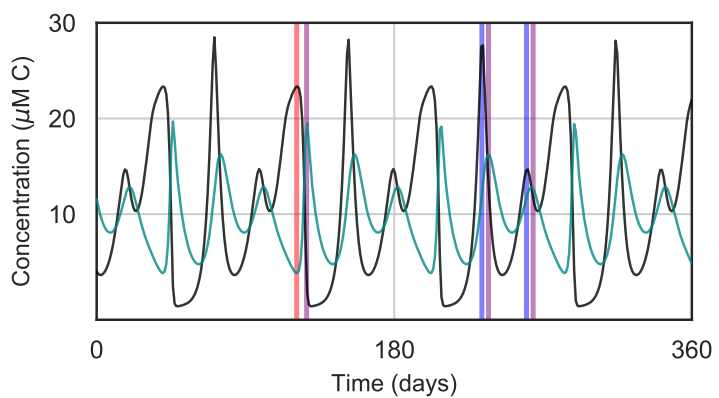

E

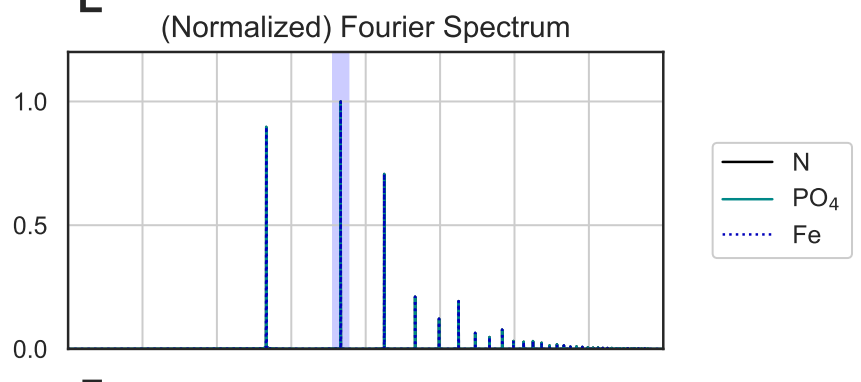

F

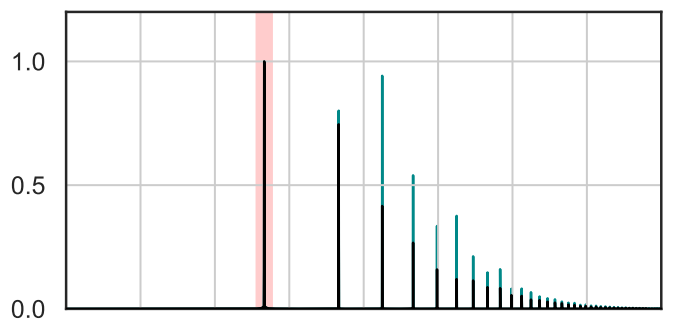

G

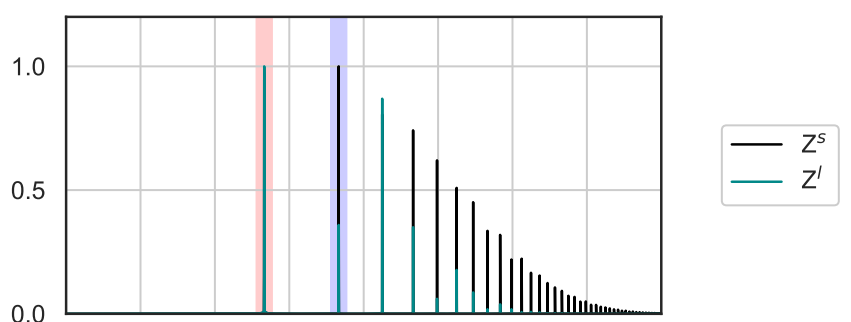

H

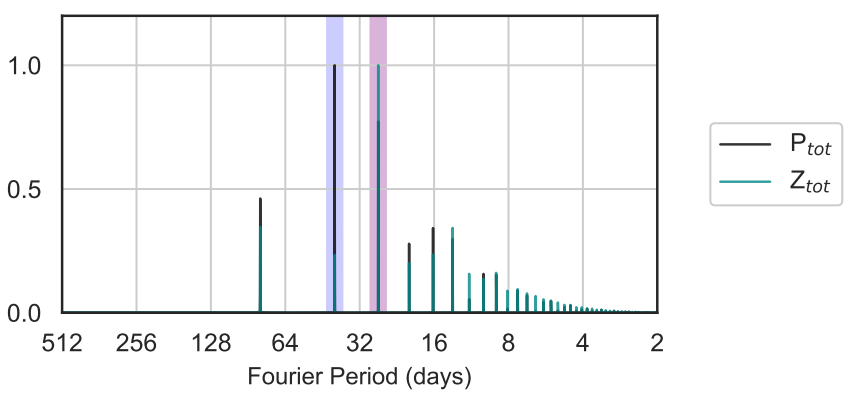

Figure 3: Time series of the last year (left column, panels A-E) and frequency spectra of the last 50 years (right column, panels F-J) from a 200 year simulation of the SimpleCom (isolated Z-oscillations) experiment. The rows correspond to (top) nutrients, (second) phytoplankton, (third) zooplankton, and (bottom) total phytoplankton and total zooplankton. See legends for curve identification. The red vertical line in panels $\mathrm{B}$ and $\mathrm{C}$ corresponds to a peak in $P_{1}^{s}$. In the spectra plots, dominant periods are indicated by: red shadings for individual phytoplankton and large zooplankton (approx. 81 days); blue shadings for nutrients, total phytoplankton, and small zooplankton (approx. 40 days); and purple shadings for nutrients and total phytoplankton (approx. 27 days). 
WeakPred

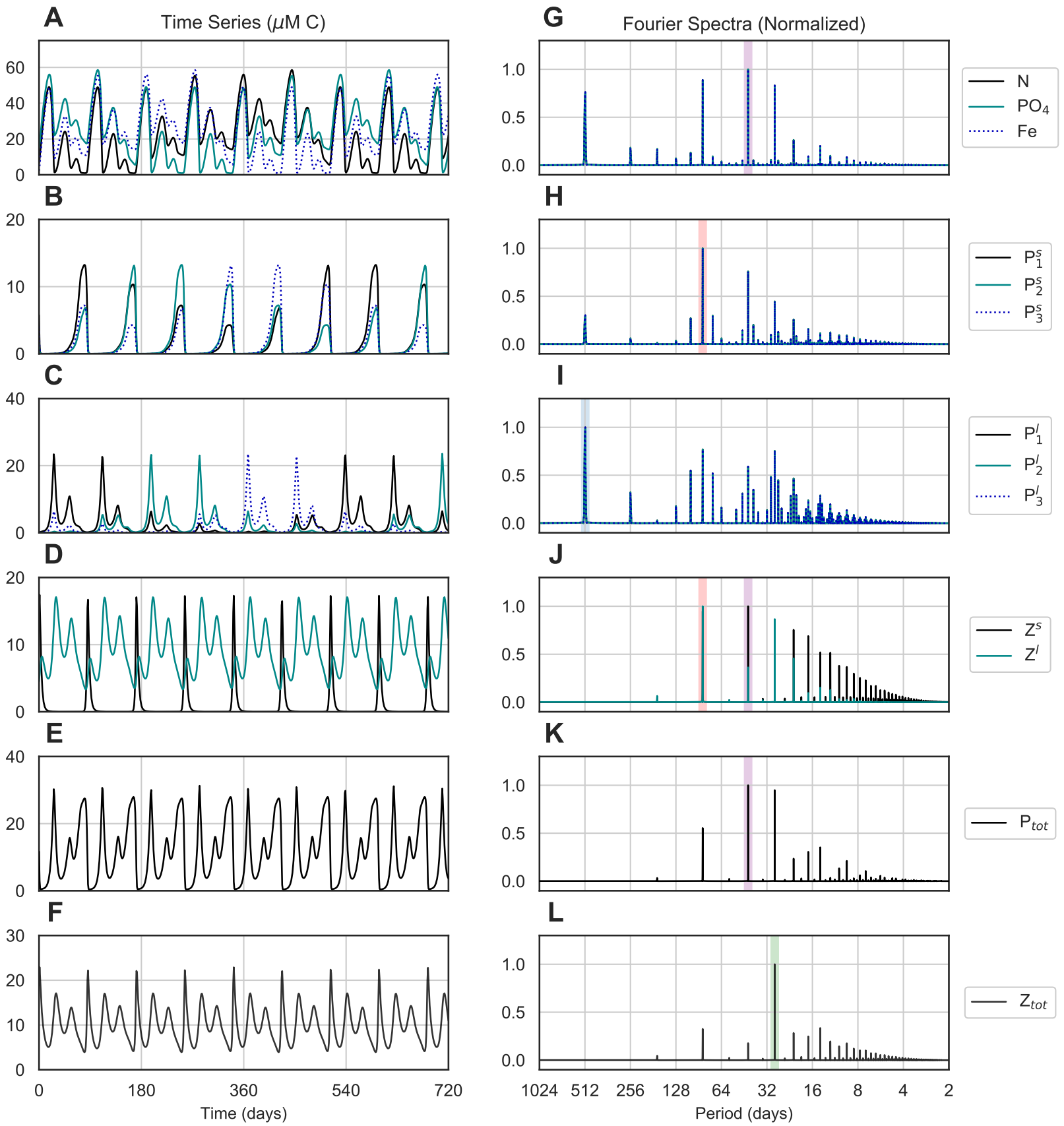

Figure 4: The time series (first column) and frequency spectra (second column) for phytoplankton, nutrient, and zooplankton compartments from a 200 year run of the WeakPred simulation. See legends for curve identification. The last two years of the time series are shown, and the last 150 years of the simulation were used to compute the spectra. In the spectra plots, dominant periods are indicated by: red shadings for the small phytoplankton and large zooplankton (approx. 85 days); blue shadings for the large phytoplankton (approx. 509 days); green shadings for the total zooplankton (approx. 28 days); and purple shadings for the total phytoplankton and small zooplankton (approx. 43 days). 


\subsection{Case WeakPred: The full system with distinct $R$ - and Z-oscillations}

Here we consider an example simulation in which all compartments of the full model equations (1) are active, using the parameters given in Table 1. The results can be seen in Figure 4. From the plots of $N$, $P_{1}^{s}$ and $P_{1}^{l}$, we see that both $\mathrm{R}$ - and Z-oscillations are present, and can be easily distinguished. The low frequency peak in panel I, with a period of approximately 514 days, is indicative of R-oscillations: analogous species $P_{1}^{s}$ and $P_{1}^{l}$ evolve together, while nitrogen is depleted and restored. A similar pattern exists between phosphate, $P_{2}^{s}$ and $P_{2}^{l}$, and amongst iron, $P_{3}^{s}$ and $P_{3}^{l}$.

By contrast, the high frequency patterns of alternating dominance between the small and large phytoplankton resemble those of the SimpleCom simulation; the large phytoplankton exhibit a double-peaked pattern, as before, while the small phytoplankton are single-peaked, with low concentrations of biomass away from the peaks. And like in the SimpleCom simulation, peaks in the zooplankton series follow their phytoplankton counterparts. The dominant period of the total phytoplankton, whose peaks reflect those of the alternating small and large phytoplankton, is 28 days.

\subsection{Case StrongPred: The full system with chaotic interactions}

In this last example, the grazing pressure is increased relative to the WeakPred simulation, with grazing rates $g^{s}, g^{l}$ set to 1.15 times the values given in Table 1 . The result is a simulation that exhibits more complex behavior, as shown by the time series and frequency spectra in Figure 5. The dominant period of the total phytoplankton and zooplankton (purple vertical shading in spectra plots) is roughly 31 days, and the dominant period of the nutrient and small zooplankton (green vertical shading) is roughly 64 days. There are several properties that distinguish this scenario from the WeakPred case. First, the spectrum is much more broadband, with dominant periods appearing more like clusters than individual peaks. Second, the time series exhibits low frequency variations in amplitude that are not present in WeakPred: an entire WeakPred cycle is visible within a two year window, whereas that is not the case for the StrongPred simulation. Third, in WeakPred (and in SimpleCom), Z-oscillations take place between analogous small and large phytoplankton.

For the individual phytoplankton, the dominant period never resolves. The reason for this becomes clear in Figure 6, which shows the last 50 years of an extended 500 year StrongPred run. The series exhibits heteroclinic cycles of increasing periodicity until roughly 35 years into the plotted series (indicated by the orange vertical line), where there is a marked shift in the phytoplankton and nutrient series. From this point until the end of the run, $P_{1}^{l}$ is present at a low concentration and continues to oscillate with the other species. This regime shift indicates an aperiodicity in the series, making the Fourier decomposition a less useful tool for understanding the nature of the oscillations. This is confirmed by looking at the frequency spectra in panels D, E, and F (taken from the last 400 years of the 200 year run). We see that the spectrum is quite broadband compared with the narrow high frequency peaks observed in previous simulations, shown in Figures 4 and 5.

\section{Intrinsic time scales of community change}

In this section we use large sets of simulations to sample swaths of parameter space and explore the nature of the emergent frequencies. Specifically, we vary a subset of parameters involved in the phytoplankton growth 


\section{StrongPred}
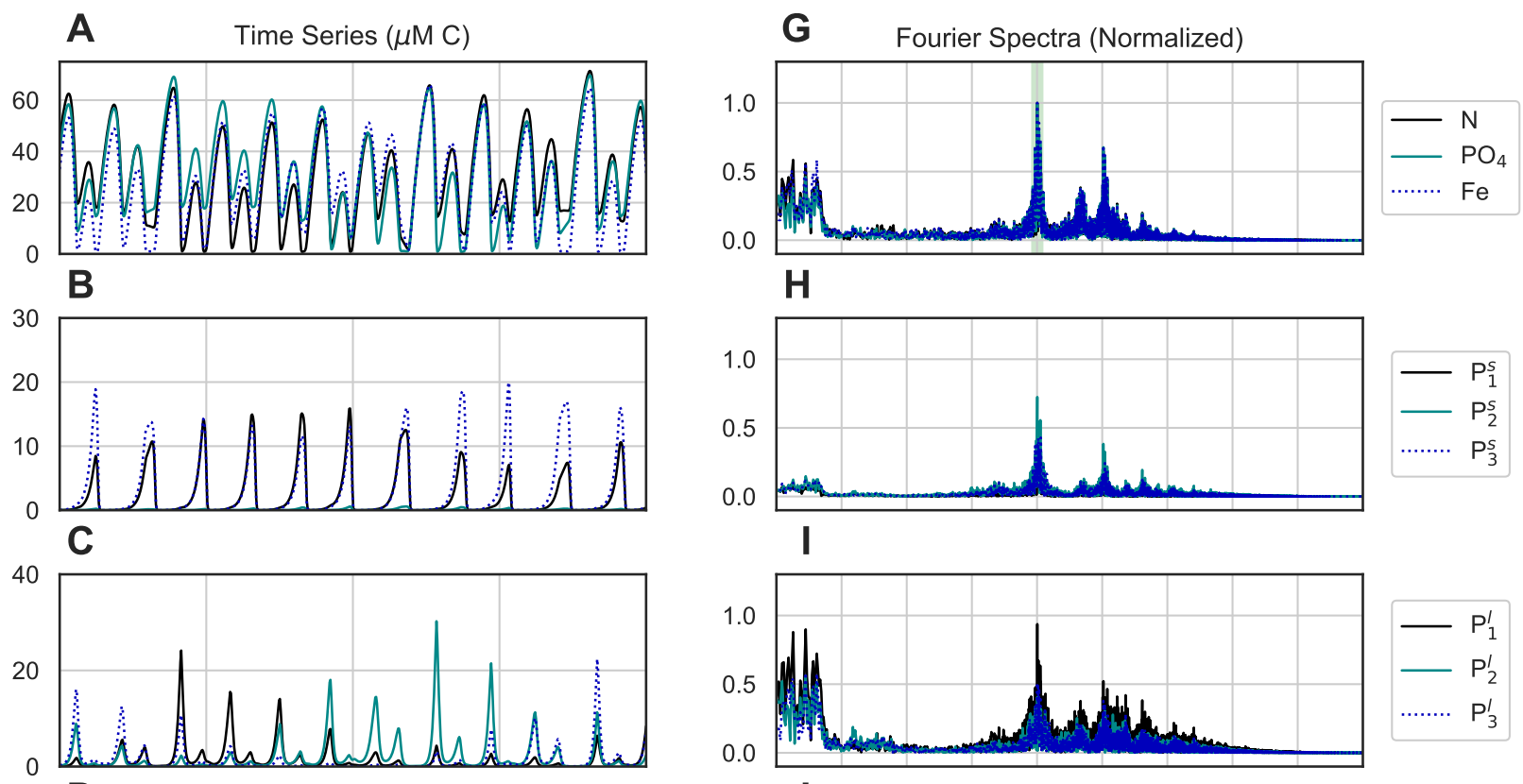

D
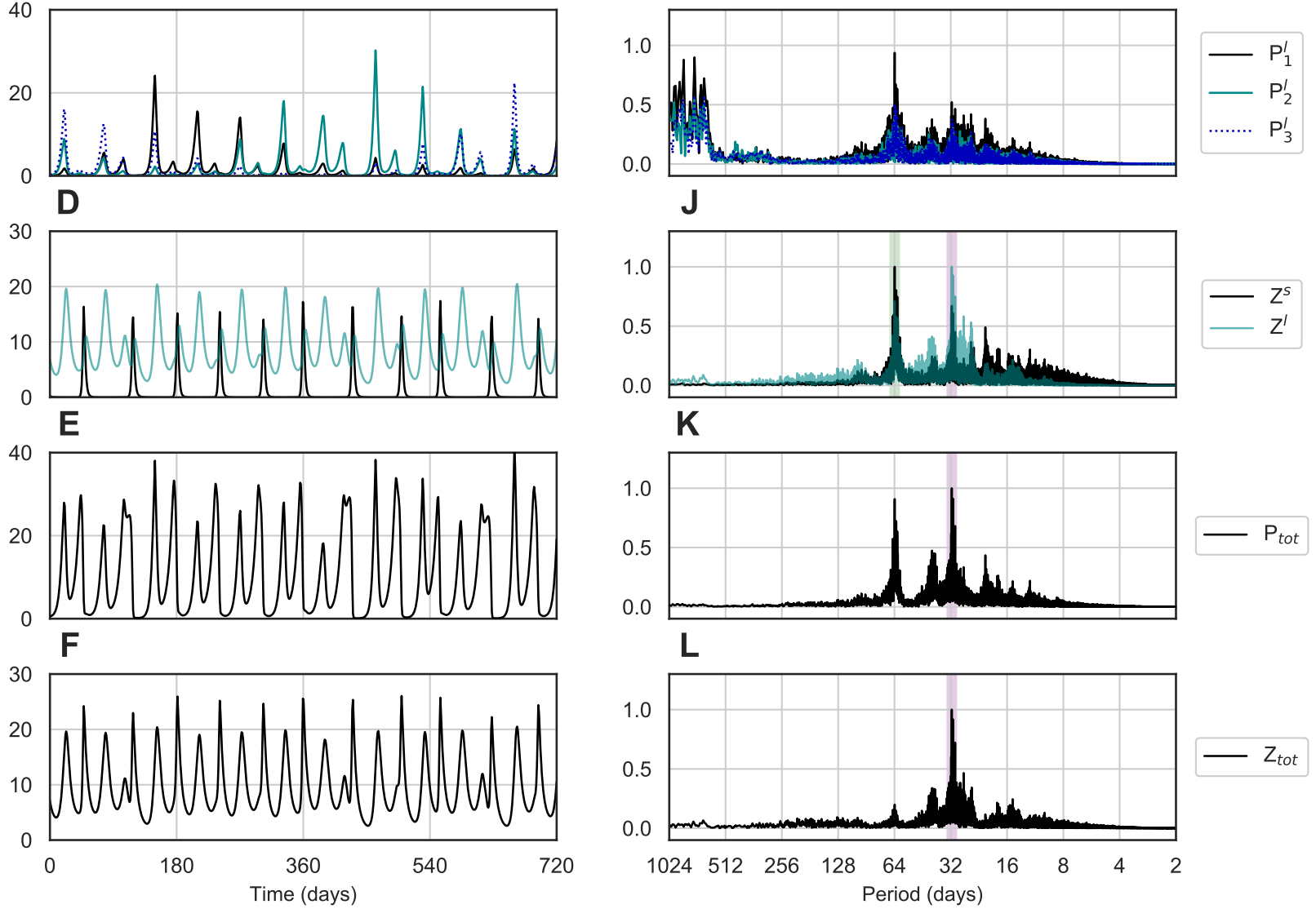

Figure 5: The time series and frequency spectra for the StrongPred simulation, with the same layout as for Figure 4 . Two dominant periods occur at approximately 64 days for nutrients and small zooplankton (green shading) and 31 days for total phytoplankton and large/total zooplankton (purple shading). But there is also a low frequency component that does not fully resolve, as indicated by the lack of a dominant period in the individual phytoplankton spectra. 
StrongPred

A

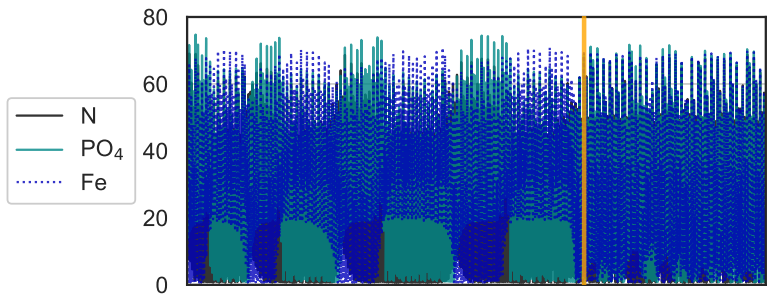

B

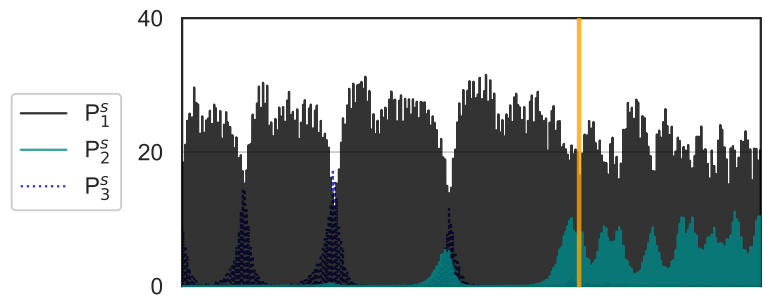

C

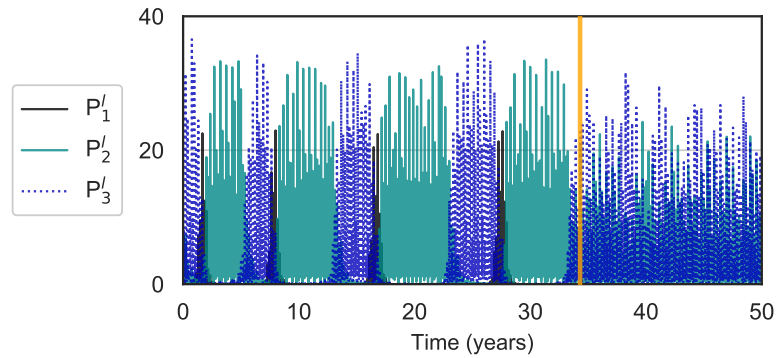

D

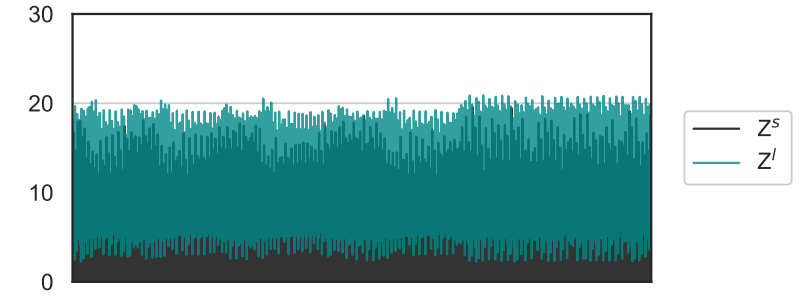

E

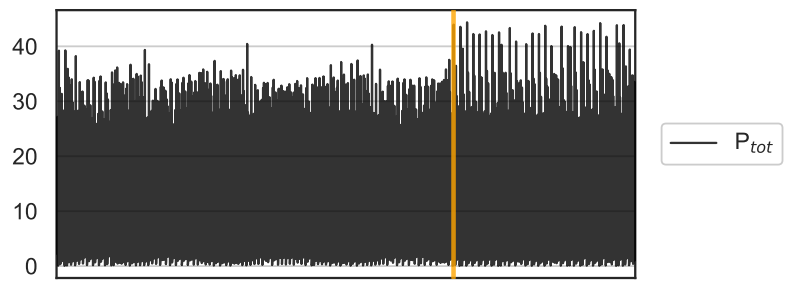

F

20

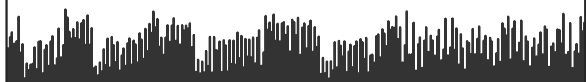

10

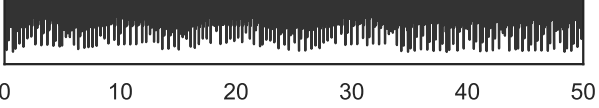

Figure 6: The last 50 years of an extended 500 year StrongPred simulation, highlighting a notable regime shift indicated by the orange vertical line. This shift is preceded by clear heteroclinic cycles, characterized by oscillations whose periods lengthen with each iteration, in the nutrient and phytoplankton compartments. 


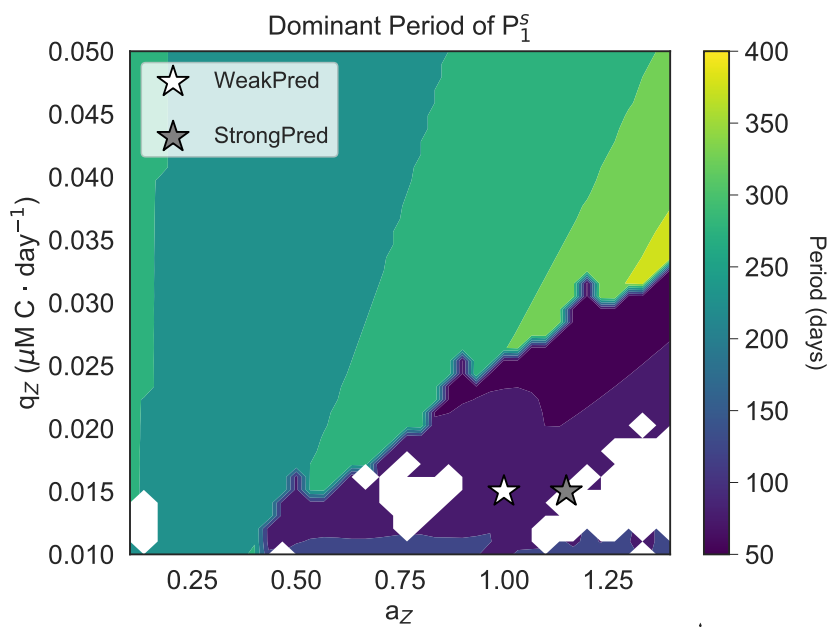

Figure 7: Dominant period for $P_{1}^{s}$ as a function of zooplankton mortality $m_{Z}$ and grazing rate scaling factor $a_{Z}$. There are three primary regimes: domination by slow R-oscillations; domination by fast Z-oscillations; and aperiodic regimes where the dominant period never resolves (shown in white).

and decay rates, i.e. grazing rates, zooplankton mortality rate, the nondimensional scaling factor $c_{\max }$ for the stoichiometry matrix (3), and the nondimensional scaling factor $k_{\min }$ for the half-saturation matrix (4).

We first focus on controlling Z-oscillations by varying the quadratic zooplankton mortality rate $m_{Z}$, and the grazing rates $g^{s}$ and $g^{l}$. We used the same multiplicative coefficient $a_{Z}$ to scale the large and the small grazing rate as $a_{Z} g^{s}$ and $a_{Z} g^{l}$ (e.g. the StrongPred example used $a_{Z}=1.15$ ). The parameter range used for these sweeps is

$$
0.01 \leq m_{Z} \leq 0.05 \text { and } \quad 0.1 \leq a_{Z} \leq 1.5
$$

where recall that the values for $m_{Z}$ have units $\mu$ mol $\mathrm{C}$ day ${ }^{-1}$. For each sweep, we assigned 40 possible linearly-spaced values per parameter, for a total of 1600 simulations. Each simulation was run for 200 years and the last 150 were used for analysis.

Figure 7 shows the dominant period of $P_{1}^{s}$ as a function of $m_{Z}$ and $a_{Z}$. There are three primary regimes: domination by slow R-oscillations; domination by fast Z-oscillations; and regimes where a dominant period never resolves over the 150 year period considered (shown in white). In the regime where R-oscillations dominate, the dominant period tends to increase with the grazing pressure. When zooplankton reduce phytoplankton biomass, they also reduce the rate at which the phytoplankton deplete nutrients. This increases the time it takes a new nutrient to become limiting and a new species to become dominant. Furthermore, the next dominant species invades at a slower rate because phytoplankton growth rates are inhibited. Thus, grazing interferes with the species succession mechanism.

We can better understand how enhanced grazing affects species succession by examining the dominant period over a range of saturation and stoichiometric coefficients. The time-scale of R-oscillations depends on the value of the parameters that control these oscillations, i.e. in our case $c_{\max }$ and $k_{\min }$ (refer to section 3.1 for an explanation). To examine how these key parameters impact the frequency of oscillations, we started from the default set of parameters in Table 1 and varied them over a range that respects their constraints: 


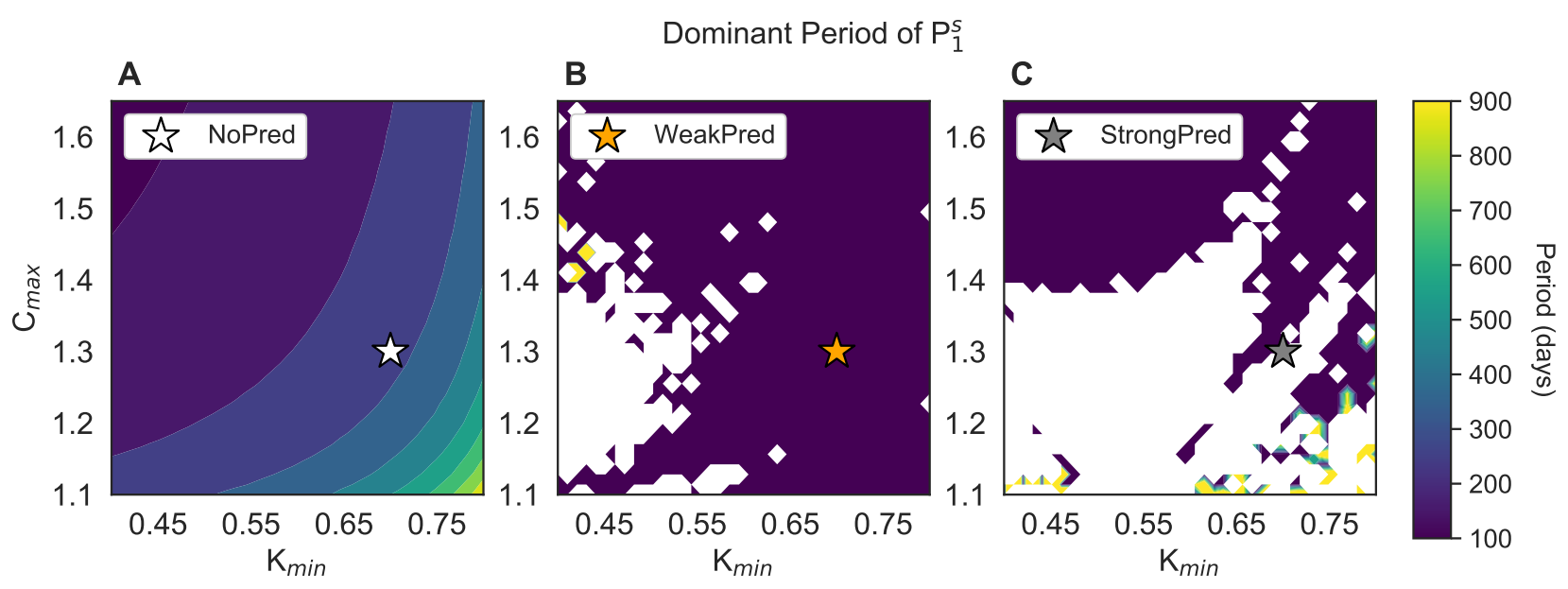

Figure 8: Dominant period of $P_{1}^{s}$ for sweeps over $c_{\max }$ and $k_{\min }$, in order of increasing grazing pressure from left to right. White regions indicate cases where no dominant period emerges, due to aperiodicity. As the grazing pressure increases, the dominant period is less likely to resolve over the considered range of parameters.

$k_{\min }<1$ and $c_{\max }>1$ :

$$
0.4 \leq k_{\min } \leq 0.8 \text { and } 1.1 \leq c_{\max } \leq 1.65
$$

The range chosen is just large enough to clearly illustrate the dependence on the parameters over a range of time scales, from intraseasonal to interannual.

Again, we assigned 40 possible linearly-spaced values for each of the sweep parameters, $k_{\min }$ and $c_{\max }$, and consider three combinations for the grazing parameters $\left(m_{Z}, a_{Z}\right):(0.05,1)$ (weak grazing); $(0.015,1)$ (intermediate grazing); and $(0.015,1.15)$ (strong grazing). We ran each simulation for 200 years and used the last 150 years for analysis. Figure 8 shows the dominant period of $P_{1}^{s}$ for the three sweeps, in order of increasing grazing pressure, from left to right. Panel A shows that under weak grazing, the expected relationship between the sweep parameters and the succession time holds: larger values of $c_{\max }$ and smaller values of $k_{\text {min }}$ lead to faster succession times. In the other two panels, the regions in white indicate that a dominant period never resolves due to aperiodicity. Most of the parameter space in panel C, where grazing is strongest, has dominant periods that never resolve.

\section{Discussion and Conclusion}

Partitioning the observed variability in planktonic ecosystems and community composition between intrinsic and external sources is a difficult task. But a reasonable first step, which we have taken in this study, is to model one kind of variability (intrinsic, in our case) and the time scales on which it occurs. To do so, we developed and explored a zero-dimensional ecosystem model that describes a range of possible interactions between phytoplankton, nutrients, and zooplankton. The model supports two kinds of oscillations, which have been previously described in the literature and which we call R-oscillations and Z-oscillations. R-oscillations describe patterns of species succession, while Z-oscillations are predator-prey limit cycles of total biomass. Previous studies have incorporated one type of oscillation or the other into their models, but we are not aware of any that have studied them simultaneously. And there is a dearth of knowledge on the time scales of these oscillations in a realistic open ocean system. 
We found that the species succession time for R-oscillations depends on the phytoplankton growth rates at high and low nutrient concentrations. In our model, these depend strongly on two parameters: $c_{\max }$, which controls the depletion rate of the nutrient in greatest abundance; and $k_{\min }$, which controls the growth rate of the next phytoplankton species in line to invade and dominate the system. Over the range of parameters in (6), we saw R-oscillations in the individual phytoplankton time series that ranged from roughly 100 to 900 days under predation-free conditions. Predator-prey Z-oscillations, on the other hand, consistently occurred on time scales not exceeding 60 days. When the two kinds of oscillations interacted, R-oscillations became even slower due to a top-down control on the rate of phytoplankton growth/nutrient depletion. And in the aperiodic scenarios where the dominant period never resolves, distinct regimes emerged over decadal (or longer) time scales.

The specific periods of oscillation and frequency of chaotic regime shifts are likely highly dependent on the model parameters and structure. However, the wide range of time scales on which the community structure and biomass varies is consistent with observations from laboratory data. The mesocosm experiment from Benincà et al. (2008) mentioned in our introduction (Section 1) contains multiple time scales of variability in species composition and biomass, and exhibits chaotic tendencies. While the structure of the food web is different from our modeling experiment (it contains only two nutrients but additional compartments for bacteria, detritus and detritivores), the results suggest that non-equilibrium dynamics play a key role in shaping ecosystems. Our model examines this same idea via a particular set of mechanisms (namely R- and Z-oscillations).

Though our model is suitable for this study in many ways, it also has some clear limitations. First, only six phytoplankton species are included with two feeding strategies represented (small gleaners and large opportunists), whereas there are tens of thousands of species in the real ocean with a continuum of sizes and optimal growth conditions. Second, we assume that any intrinsic variability reflected in the data must be attributed to one or two prescribed mechanisms. By design, we have omitted contributions to variability from stochasticity in the environment, which may affect the evolution of biomass and community composition in a nontrivial way, even in systems with minimal seasonality. We leave these avenues of investigation open for future studies.

From the results above, we determined that intrinsic oscillations can occur on broad range of time scales. These oscillations are not tied to any physical phenomena, such as seasonal changes in light or interannual changes in enviromental parameters, but they share overlap in their frequency ranges. Thus, we believe that phytoplankton may exhibit complex responses to many external sources of variability. The degree to which the nature of these responses diverges from the external variability will likely depend on the strength of the forcings and the region of interest. At highly seasonal latitudes, R- and Z-oscillations would be inhibited by winter mixing, which reduces predator-prey encounters and the amount of available light and nutrient. Phytoplankton evolution may therefore be phase locked to seasonal changes, as reflected in SeaWiFS data from the North Atlantic, for example in (Behrenfeld, 2010). The idea is also reflected in (Winder and Cloern, 2010), which contrasts a strong annual bloom for an ecosystem in the Wadden Sea (North Atlantic) with one in Lake Hatchineha (Florida), whose blooms are irregular and occur on shorter time scales.

In contrast, coastal upwelling "hotspots" are characterized by a persistent inflow of nutrients from the 
deep and elevated predatory pressure - conditions that are conducive to domination by intrinsic oscillations. Evidence of intrinsic long-term variability in coastal communities is also reflected in phytoplankton time series. Bode et al. (2015) found from the RADIALES dataset, collected off the northwest coast of the Iberian peninsula, that phytoplankton variability tends to be stochastic. Trends emerge over interannual and decadal time scales that do not correlate meaningfully with physical properties such as temperature and and stratification. Cianelli et al. (2017) also concluded that the structure of coastal ecosystems in the Gulf of Naples is primarily influenced by intrinsic factors, with physical contributions aiding biodiversity by diluting ecosystems and preventing dominance by a handful of species.

Another way to frame the above discussion is to ask how the amplitude of intrinsic variability compares to that of external variability under a variety of physical conditions. The oscillations in this study were quite large for both individual compartments (R-oscillations) and in total biomass (Z-oscillations). We expect that the presence of external oscillations will reduce the amplitude of the intrinsic contributions. But the degree to which this happens will depend on the strength of the relevant forcings. We intend to explore this open question in a follow-up study.

\section{Acknowledgements}

The authors thank Stephanie Dutkiewicz and Olivier Aumont for early feedback on this work. BM, KSS, and ML gratefully acknowledge support from the New York University Abu Dhabi Institute, through its Center for Prototype Climate Modeling. ML gratefully acknowledges support from TOSCA-CNES and ANR-SOBUMS (contract ANR-16-CE01-0014).

\section{Appendix A. Simplified Model}

Here, we present a simplified ecosystem model based on the equations outlined in Section 2. We include two nutrients $R_{1}$ and $R_{2}$; two small phytoplankton $P_{1}$ and $P_{2}$; and one zooplankton $Z$. We use the same symbols for our parameters, but we remove superscripts and abandon the concept of size classes.

The equations are

$$
\begin{aligned}
& \frac{d R_{1}}{d t}=\tau\left(S_{1}-R_{1}\right)-\mu\left[C_{11} \min \left\{\frac{R_{1}}{K_{11}+R_{1}}, \frac{R_{2}}{K_{21}+R_{2}}\right\} P_{1}+C_{12} \min \left\{\frac{R_{1}}{K_{12}+R_{1}}, \frac{R_{2}}{K_{22}+R_{2}}\right\} P_{2}\right] \\
& \frac{d R_{2}}{d t}=\tau\left(S_{2}-R_{2}\right)-\mu\left[C_{21} \min \left\{\frac{R_{1}}{K_{11}+R_{1}}, \frac{R_{2}}{K_{21}+R_{2}}\right\} P_{1}+C_{22} \min \left\{\frac{R_{1}}{K_{12}+R_{1}}, \frac{R_{2}}{K_{22}+R_{2}}\right\} P_{2}\right], \\
& \frac{d P_{1}}{d t}=-\tau P_{1}+\left[\mu \min \left\{\frac{R_{1}}{K_{11}+R_{1}}, \frac{R_{2}}{K_{21}+R_{2}}\right\}-m_{P}-\frac{g Z}{K_{Z}+P_{1}+P_{2}}\right] P_{1} \\
& \frac{d P_{2}}{d t}=-\tau P_{2}+\left[\mu \min \left\{\frac{R_{1}}{K_{12}+R_{1}}, \frac{R_{2}}{K_{22}+R_{2}}\right\}-m_{P}-\frac{g Z}{K_{Z}+P_{1}+P_{2}}\right] P_{2} \\
& \frac{d Z}{d t}=-\tau Z+\frac{g Z}{K_{Z}+P_{1}+P_{2}}\left(P_{1}+P_{2}\right)-m_{Z} Z^{2}
\end{aligned}
$$

There are two nutrient currencies $R_{1}$ and $R_{2}$, and we can convert from phytoplankton units (carbon) to nutrient units via multiplication by the stoichiometric coefficients $C_{j i}$. The stoichiometric coefficients for $Z$, 
380

which we may call $C_{j}^{Z}$, do not appear in the equations because zooplankton do not introduce a loss term to the nutrient equations.

We can examine the evolution of $\phi_{j}$, or the total amount of $R_{j}$ in the system

$$
\begin{aligned}
& \phi_{1}=R_{1}+C_{11} P_{1}+C_{12} P_{2}+C_{1}^{Z} Z \\
& \phi_{2}=R_{2}+C_{21} P_{1}+C_{22} P_{2}+C_{2}^{Z} Z
\end{aligned}
$$

If we differentiate $\phi_{j}$ in time, we have a balance between: nutrient inflow, outflow from all compartments, and phytoplankton/zooplankton mortality

$$
\begin{aligned}
\frac{d \phi_{1}}{d t} & =\tau\left(S_{1}-\phi_{1}\right)-m_{P}\left(C_{11} P_{1}+C_{12} P_{2}\right)-C_{1}^{Z} m_{Z}^{2} \\
\frac{d \phi_{2}}{d t} & =\tau\left(S_{2}-\phi_{2}\right)-m_{P}\left(C_{21} P_{1}+C_{22} P_{2}\right)-C_{2}^{Z} m_{Z}^{2}
\end{aligned}
$$

Note that these equations do not depend on growth or uptake terms, as these processes are completely balanced and cancel upon adding up the right-hand sides of the equations.

\section{References}

Alvain, S., Moulin, C., Dandonneau, Y., Loisel, H., 2008. Seasonal distribution and succession of dominant phytoplankton groups in the global ocean : A satellite view. Global Biogeochemical Cycles 22, 1-15. doi:10.1029/2007GB003154.

Aumont, O., Maier-Reimer, E., Blain, S., Monfray, P., 2003. An ecosystem model of the global ocean including $\mathrm{Fe}$, Si, P colimitations. Global Biogeochemical Cycles 17. doi:10.1029/2001gb001745.

Aumont, O., Maury, O., Lefort, S., Bopp, L., 2018. Evaluating the Potential Impacts of the Diurnal Vertical Migration by Marine Organisms on Marine Biogeochemistry. Global Biogeochemical Cycles 32, 1622-1643. doi:10.1029/2018GB005886.

Aumont, O., Tagliabue, A., Bopp, L., Gehlen, M., 2015. PISCES-v2: an ocean biogeochemical model for carbon and ecosystem studies. Geoscientific Model Development 8, 2465-2513. doi:10.5194/ gmd-8-2465-2015.

Behrenfeld, M.J., 2010. Abandoning Sverdrup's Critical Depth Hypothesis on phytoplankton blooms. Ecology 91, 977-989. URL: http://www. esajournals .org/doi/abs/10 .1890/09-1207.1, doi:10 .1890/09-1207. 1.

Behrenfeld, M.J., O’Malley, R.T., Siegel, D.A., McClain, C.R., Sarmiento, J.L., Feldman, G.C., Milligan, A.J., Falkowski, P.G., Letelier, R.M., Boss, E.S., 2006. Climate-driven trends in contemporary ocean productivity. Nature 444, 752-755. doi:10.1038/nature05317.

Benincà, E., Ballantine, B., Ellner, S.P., Huisman, J., 2015. Species fluctuations sustained by a cyclic succession at the edge of chaos. Proceedings of the National Academy of Sciences of the United States of America 112, 6389-94. URL: http://www.ncbi.nlm.nih.gov/pubmed/25902520http://www.pubmedcentral. nih.gov/articlerender.fcgi?artid=PMC4443354, doi:10.1073/pnas . 1421968112. 
409

410

411

412

413

414

415

416

417

418

419

420

421

422

423

424

425

426

427

428

429

430

431

432

433

434

435

436

437

438

439

440

441

Benincà, E., Huisman, J., Heerkloss, R., Johnk, K.D., Branco, P., Van Nes, E.H., Scheffer, M., Ellner, S.P., 2008. Chaos in a long-term experiment with a plankton community. Nature Letters 451. doi:10.1038/ nature06512.

Blasius, B., Rudolf, L., Weithoff, G., Gaedke, U., Fussmann, G.F., 2019. Long-term cyclic persistence and phase signature in an experimental predator-prey system. Nature , 1-36URL: http://dx.doi.org/10. 1038/s41586-019-1857-0, doi:10.1038/nature11356.

Bode, A., Estévez, M.G., Varela, M., Vilar, J.A., 2015. Annual trend patterns of phytoplankton species abundance belie homogeneous taxonomical group responses to climate in the NE Atlantic upwelling. Marine Environmental Research 110,81-91. doi:10.1016/j.marenvres.2015.07.017.

Bopp, L., Resplandy, L., Orr, J.C., Doney, S.C., Dunne, J.P., Gehlen, M., Halloran, P., Heinze, C., Ilyina, T., Séférian, R., Tjiputra, J., Vichi, M., 2013. Multiple stressors of ocean ecosystems in the 21st century: Projections with CMIP5 models. Biogeosciences 10, 6225-6245. doi:10.5194/bg-10-6225-2013.

Carranza, M.M., Gille, S.T., 2014. Southern Ocean wind-driven entrainment enhances satellite chlorophyll-a through the summer. Journal of Geophysical Research: Oceans , 2121-2128doi:10.1002/jgrc. 20224.

Chavez, F.P., Messi, M., Pennington, J.T., 2011. Marine Primary Production in Relation to Climate Variability and Change. Annu. Rev. Mar. Sci. 3, 227-60. doi:10.1146/annurev.marine.010908.163917.

Cianelli, D., D’Alelio, D., Uttieri, M., Sarno, D., Zingone, A., Zambianchi, E., D'Alcalà, M.R., 2017. Disentangling physical and biological drivers of phytoplankton dynamics in a coastal system. Scientific Reports 7, 1-15. doi:10.1038/s41598-017-15880-x.

Cropp, R., Norbury, J., 2009. Parameterizing plankton functional type models: Insights from a dynamical systems perspective. Journal of Plankton Research 31, 939-963. doi:10.1093/plankt/fbp042.

Dakos, V., Benincà, E., Van Nes, E.H., Philippart, C.J., Scheffer, M., Huisman, J., 2009. Interannual variability in species composition explained as seasonally entrained chaos. Proceedings of the Royal Society B: Biological Sciences 276, 2871-2880. doi:10.1098/rspb. 2009. 0584.

Demarcq, H., Reygondeau, G., Alvain, S., Vantrepotte, V., 2012. Monitoring marine phytoplankton seasonality from space. Remote Sensing of Environment 117, 211-222. URL: http://dx.doi.org/10.1016/j . rse.2011.09.019, doi:10.1016/j.rse.2011.09.019.

d'Ovidio, F., De Monte, S., Alvain, S., Dandonneau, Y., Lévy, M., 2010. Fluid dynamical niches of phytoplankton types. Proceedings of the National Academy of Sciences of the United States of America 107, 18366-18370. doi:10.1073/pnas. 1004620107.

Dutkiewicz, S., Follows, M.J., Bragg, J.G., 2009. Modeling the coupling of ocean ecology and biogeochemistry. Global Biogeochemical Cycles 23. URL: http://doi.wiley.com/10.1029/2008GB003405, doi:10.1029/ 2008 GB003405. 
Dutkiewicz, S., Hickman, A.E., Jahn, O., Henson, S., Beaulieu, C., Monier, E., 2019. Ocean colour signature of climate change. Nature Communications 10. URL: http://dx.doi.org/10.1038/ s41467-019-08457-x, doi:10.1038/s41467-019-08457-x.

Edwards, A.M., Brindley, J., 1996. Oscillatory behaviour in a three-component plankton population model. Dynamical Systems 11, 347-370. doi:10.1080/02681119608806231.

Fasham, M.J., Ducklow, H.W., McKelvie, S.M., 1990. A nitrogen-based model of plankton dynamics in the oceanic mixed layer. Journal of Marine Research 48, 591-639. doi:10.1357/002224090784984678.

Fauchereau, N., Tagliabue, A., Bopp, L., Monteiro, P.M., 2011. The response of phytoplankton biomass to transient mixing events in the Southern Ocean. Geophysical Research Letters 38, 1-6. doi:10.1029/ 2011 GL048498.

Follows, M.J., Dutkiewicz, S., Grant, S., Chisholm, S.W., 2007. Emergent biogeography of microbial communities in a model ocean. Science (New York, N.Y.) 315, 1843-6. URL: http://www.ncbi.nlm.nih. gov/pubmed/17395828, doi:10.1126/science.1138544.

Fussmann, G.F., Ellner, S.P., Shertzer, K.W., Hairston N.G., J., 2000. Crossing the hopf bifurcation in a live predator-prey system. Science 290, 1358-1360. doi:10.1126/science.290.5495.1358.

Gilpin, M.E., 1979. Spiral Chaos in a Predator-Prey Model. The American Naturalist 113, 306-308.

Gothlich, L., Oschlies, A., 2015. Disturbance characteristics determine the timescale of competitive exclusion in a phytoplankton model. Ecological Modelling 296, 126-135. URL: http://dx.doi.org/10.1016/j. ecolmodel.2014.10.033, doi:10.1016/j.ecolmodel.2014.10.033.

Hastings, A., 2020. Long-term predator-prey cycles finally achieved in the lab. doi:10.1038/ d41586-019-03603-3.

Hindmarsh, A.C., 1982. ODEPACK, A Systematized Collection of ODE Solvers. IMACS Transactions on Scientific Computation 1, 55-64.

Huisman, J., Pham Thi, N.N., Karl, D.M., Sommeijer, B., 2006. Reduced mixing generates oscillations and chaos in the oceanic deep chlorophyll maximum. Nature 439, 322-325. doi:10.1038/nature04245.

Huisman, J., Weissing, F.J., 1999. Biodiversity of plankton by species oscillations and chaos. Nature 402, 407-410. doi:10.1038/46540.

Huisman, J., Weissing, F.J., 2001. Biological conditions for oscillations and chaos generated by multispecies competition. Ecology 82, 2682-2695. URL: http://doi.wiley.com/10.1890/0012-9658(2001) 082 [2682:BCFOAC] 2. . . C0; 2, doi:10 .1890/0012-9658 (2001) 082 [2682:BCFOAC] 2 . . . C0; 2.

Keerthi, M.G., Levy, M., Aumont, O., Lengaigne, M., Antoine, D., 2020. Contrasted Contribution of Intraseasonal Time Scales to Surface Chlorophyll Variations in a Bloom and an Oligotrophic Regime. Journal of Geophysical Research: Oceans 125. doi:10.1029/2019jc015701. 
475

476

477

478

479

480

481

482

483

484

485

486

487

488

489

490

491

492

493

494

495

496

497

498

499

500

501

502

503

504

505

506

507

Klausmeier, C.A., Litchman, E., Daufresne, T., Levin, S., 2004. Optimal nitrogen-to-phosphorus stoichiometry of phytoplankton. Nature 429, 171-174. doi:1.1029/2001GL014649.

Lévy, M., Franks, P.J., Smith, K.S., 2018. The role of submesoscale currents in structuring marine ecosystems. Nature communications 9, 4758. doi:10.1038/s41467-018-07059-3.

Mahadevan, A., D’Asaro, E., Lee, C., Perry, M.J., 2012. Eddy-driven stratification initiates North Atlantic spring phytoplankton blooms. Science (New York, N.Y.) 337, 54-8. URL: http://www.sciencemag.org/ content/337/6090/54. abstract, doi:10.1126/science. 1218740 .

Martinez, E., Antoine, D., Ortenzio, F.D., Gentili, B., 2009. Climate-Driven Basin-Scale Decadal Oscillations of Oceanic Phytoplankton. Science 1253. doi:10.1126/science.1177012.

Mayot, N., D’Ortenzio, F., Uitz, J., Gentili, B., Ras, J., Vellucci, V., Golbol, M., Antoine, D., Claustre, H., 2017. Influence of the Phytoplankton Community Structure on the Spring and Annual Primary Production in the Northwestern Mediterranean Sea. Journal of Geophysical Research: Oceans 122, 9918-9936. doi:10. 1002/2016JC012668.

Menkes, C.E., Lengaigne, M., Lévy, M., Ethé, C., Bopp, L., Aumont, O., Vincent, E., Vialard, J., Jullien, S., 2016. Global impact of tropical cyclones on primary production. Global Biogeochemical Cycles 29, 767-786. doi:10.1002/2015GB005214. Received.

Messié, M., Chavez, F.P., 2017. Nutrient supply, surface currents, and plankton dynamics predict zooplankton hotspots in coastal upwelling systems. Geophysical Research Letters 44, 8979-8986. URL: https:// onlinelibrary.wiley.com/doi/full/10.1002/2017GL074322, doi:10.1002/2017GL074322.

Messié, M., Ledesma, J., Kolber, D.D., Michisaki, R.P., Foley, D.G., Chavez, F.P., $2009 . \quad$ Progress in Oceanography Potential new production estimates in four eastern boundary upwelling ecosystems. Progress in Oceanography 83, 151-158. URL: http://dx.doi.org/10.1016/j.pocean.2009.07.018, doi:10.1016/j.pocean.2009.07.018.

Millman, K.J., Aivazis, M., 2011. Python for scientists and engineers. doi:10.1109/MCSE.2011.36.

Petzold, L., 1983. Automatic selection of methods for solving stiff and nonstiff systems of ordinary differential equations. SIAM Journal on Scientific and Statistical Computing 4, 136-148.

Platt, T., White, G.N., Zhai, L., Sathyendranath, S., Roy, S., 2009. The phenology of phytoplankton blooms: Ecosystem indicators from remote sensing. Ecological Modelling 220, 3057-3069. URL: https://www-sciencedirect-com.proxy.library.nyu.edu/science/article/pii/ S0304380008005462, doi:10.1016/J .ECOLMODEL . 2008.11.022.

Poggiale, J., Eynaud, Y., Baklouti, M., 2013. Impact of periodic nutrient input rate on trophic chain properties. Ecological Complexity 14, 56-63. URL: http://dx.doi.org/10.1016/j.ecocom.2013.01. 005, doi:10.1016/j.ecocom.2013.01.005. 
508

509

510

511

512

513

514

515

516

517

518

519

520

521

522

523

524

525

526

527

528

529

530

531

532

533

534

535

536

537

538

Prowe, A.E., Pahlow, M., Dutkiewicz, S., Oschlies, A., 2014. How important is diversity for capturing environmental-change responses in ecosystem models? Biogeosciences 11, 3397-3407. doi:10.5194/ bg-11-3397-2014.

Redfield, A.C., 1934. On the proportions of organic derivatives in sea water and their relation to the composition of plankton. University Press of Liverpool.

Resplandy, L., Vialard, J., Lévy, M., Aumont, O., Dandonneau, Y., 2009. Seasonal and intraseasonal biogeochemical variability in the thermocline ridge of the southern tropical Indian Ocean. Journal of Geophysical Research: Oceans 114, 1-13. doi:10.1029/2008JC005246.

Rousseaux, C.S., Gregg, W.W., 2015. Recent decadal trends in global phytoplankton composition. Global Biogeochemical Cycles , 1674-1688doi:10.1002/2015GB005139. Received.

Salgado-Hernanz, P.M., Racault, M.F., Font-Muñoz, J.S., Basterretxea, G., 2019. Trends in phytoplankton phenology in the Mediterranean Sea based on ocean-colour remote sensing. Remote Sensing of Environment 221, 50-64. URL: https://doi.org/10.1016/j.rse.2018.10.036, doi:10.1016/j.rse.2018.10.036.

Sarmiento, J.L., Slater, R.D., Fasham, M.J.R., Ducklow, H.W., Toggweiler, J.R., Williams, R., 1993. A seasonal three-dimensional ecosystem model of nitrogen cycling in the North Atlantic euphotic zone: A comparison of model results with observations from Bermuda Station "S" and OWS "India.". Glob. Biogeochem. Cycles 7, 379 .

Sathyendranath, S., Ji, R., Browman, H.I., 2015. Revisiting Sverdrup's critical depth hypothesis. ICES Journal of Marine Science 72, 1892-1896. doi:10.1093/icesjms/fsv110.

Thomalla, S.J., Fauchereau, N., Swart, S., Monteiro, P.M., 2011. Regional scale characteristics of the seasonal cycle of chlorophyll in the Southern Ocean. Biogeosciences 8, 2849-2866. doi:10.5194/bg-8-2849-2011.

Tilman, D., 1977. Resource Competition between Plankton Algae: An Experimental and Theoretical Approach. Ecology 58, 338-348.

Tilman, D., 1985. The Resource-Ratio Hypothesis of Plant Succession. The American Naturalist 125, 827852 .

Vantrepotte, V., Mélin, F., 2011. Inter-annual variations in the SeaWiFS global chlorophyll a concentration (1997-2007). Deep-Sea Research Part I: Oceanographic Research Papers 58, 429-441. doi:10.1016/j .dsr . 2011.02 .003$.

Winder, M., Cloern, J.E., 2010. The annual cycles of phytoplankton biomass. Philosophical Transactions of the Royal Society B: Biological Sciences 365, 3215-3226. URL: http://rstb.royalsocietypublishing. org/cgi/doi/10.1098/rstb.2010.0125, doi:10.1098/rstb.2010.0125. 